\title{
Comparison of resident and intern salaries with the current living wage as a quantitative estimate of financial strain among postgraduate veterinary trainees
}

\author{
Samantha L. Morello, DVM ${ }^{1 *}$; Kai-Biu Shiu, BVMS²; Joseph Thurston, BS ${ }^{1}$ \\ 'Department of Surgical Sciences, School of Veterinary Medicine, University of Wisconsin-Madison, Madison, WI \\ 2VCA Veterinary Emergency Service and Veterinary Specialty Center, Middleton, WI \\ *Corresponding author: Dr. Morello (vetsam@gmail.com)
}

\section{OBJECTIVE}

To compare resident and intern salaries with current regional living wages as a quantitative estimate of financial strain.

\section{SAMPLE}

I52 residency programs and I4I internship programs listed with the Veterinary Internship and Residency Matching Program for the 202I-2022 training year.

\section{PROCEDURES}

Data were collected for program annual salary and location. Regional living wage for each location was determined with the Massachusetts Institute of Technology Living Wage Calculator, and annual salary was compared with living wage to estimate income surplus before and after taxes. Results for programs in academia and private practice were compared. Spearman correlation was used to determine whether program annual salary was significantly associated with regional living wage.

\section{RESULTS}

Mean \pm SD income surplus before taxes was $\$ 7,786 \pm 9,426$ for clinical residency programs, $\$ 16,672 \pm 5$, 105 for laboratory animal programs, and $\$ 5,829 \pm 8,119$ for internships. Academic residencies and internships offered salaries significantly lower than those offered in private practice, and income surpluses before and after taxes were significantly lower for academic programs than for private practice programs. There were weak and moderate, respectively, correlations between program annual salary and regional living wage for residency $(r=0.369)$ and internship $(r=0.570)$ programs.

\section{CLINICAL RELEVANCE}

Postgraduate training prolongs financial instability, and annual salaries generally do not meet the minimum income standard of a living wage. Financial stress has implications for mental health and diversity, and these findings invite deeper consideration of current remuneration practices for veterinary residents and interns.

$\mathbf{T}$ here is a price for higher education in the US, and veterinary medicine is no exception. In 2020, the cost of a 4-year veterinary education at accredited institutions in the US ranged from $\$ 170,742$ to $\$ 289,597$ for in-state residents and from $\$ 222,612$ to $\$ 481,514$ for nonresidents; these numbers are anticipated to grow along with the overall rising costs of education. ${ }^{1,2}$ In addition, $40 \%$ of veterinary students matriculating in the US with a projected graduation date of 2024 had already accrued debt from their undergraduate coursework, ${ }^{2}$ and mean educational indebtedness acquired during the veterinary degree program by the $82 \%$ of graduates who left with debt at the end of the 2020 academic year was $\$ 178,585 .^{2}$

The financial toll of education does not necessarily end at graduation. Mean annual salaries reported by the American Association of Veterinary Medical Colleges for academic internship and residency positions secured through the Veterinary Internship and Residency Matching Program for the 2020-2021 training year were $\$ 28,372^{3}$ and $\$ 35,098 .{ }^{4}$ By comparison, mean reported annual starting salaries for new veterinarian graduates in public and private practice were $\$ 71,422$ and $\$ 86,920$, respectively. 5 The low salaries for individuals who pursue postgraduate veterinary training contribute to the overall number of years of lost income for veterinarians ${ }^{6}$ and exacerbate the already high debt-to-income ratio.

The poverty threshold is considered the minimum level of income adequate to provide essential resources for a human being. In the US in 2020 for a single person under 65 , the poverty threshold was $\$ 12,760$. A living wage is a more accurate estimate of the minimum income required for an individual to meet their basic needs, such as food, housing, transportation, and clothing, and to avoid reliance on subsidies from the government and other public entities. This latter point separates the living wage from the 
poverty threshold, which does not necessarily prevent the need for federal assistance programs. The living wage varies by household type and location because of variations in necessities and costs of living imposed situationally and regionally. The living wage also does not consider funds necessary for things such as dining out, prepared meals, entertainment and other social activities, health club memberships, paying off debt, or establishing personal savings. As a minimum subsistence income, a living wage would not provide great economic security or contribute substantially to many of the other things traditionally valued as improving the quality of life and general well-being that can help counter the effects of compassion fatigue and mental illness.

The American Psychological Association has shown that, chronically, money concerns are a top source of stress in American adults. ${ }^{7}$ Financial strain and debt have been linked to depression ${ }^{8}$ and are demonstrated risk factors for suicide attempts and ideation. Financial dissatisfaction and indebtedness were associated with low well-being scores in a large survey of veterinarians, ${ }^{10,11}$ and inadequate financial reward was one of many factors implicated in burnout and job dissatisfaction among medical professionals at both the attending and resident level. ${ }^{12-17}$ Veterinary interns and residents face myriad personal and professional challenges during their years of training, and it is highly likely that, for many, financial instability detracts from their overall well-being. In the House Officer Wellbeing Study ${ }^{18}$ conducted in December 2020 by the American Association of Veterinary Medical Colleges, "problems with debt" was the most commonly reported stressful life event, with over half of respondents citing this issue. As new veterinarians enter into internships and residencies across the country, it is unknown how much financial security those individuals can expect to achieve beyond a minimum living wage when relying solely on the income provided by their training program. A more quantitative estimate of the economic remuneration and financial stability of interns and residents would provide a meaningful lens into an important area contributing to house officer well-being and may highlight a factor possibly serving to dissuade some students from applying for or even considering postgraduate training, unwittingly contributing to a lack of diversity among specialists and academic faculty.

The aim of the study reported here was to compare annual salaries for the 2021-2022 training year for a large sample of resident and internship programs with living wages in the areas where those programs were located. Our first objective was to estimate the amount of income beyond a living wage that interns and residents in private practice and academic programs would be likely to receive. Our second objective was to estimate hourly incomes for residents and interns on the basis of previously reported data regarding typical working hours for those groups ${ }^{18}$ and compare those hourly incomes with regional hourly living wages to quantitatively assess the remuneration received. Our last 2 objectives were to compare academic versus private practice training programs to determine whether one setting offered any salary advantage over the other and to determine whether program annual salaries correlated with regional living wages.

\section{Materials and Methods}

\section{Data collection}

The online Veterinary Internship and Residency Matching Program database ${ }^{19}$ was searched in May 2021 to identify clinical residency programs in the 4 categories representing the largest specialty areas (emergency medicine and critical care, small animal medicine, small animal surgery, and large animal surgery [including programs identified as equine surgery]) and to identify clinical internship programs in the small animal rotating category, which represented the largest subset of internship programs available. For comparison purposes, the database was also searched to identify residency programs under the laboratory animal and comparative medicine (LACM) category, because these programs were nonclinical in nature and often funded by the federal government and, therefore, represented an alternative perspective on remuneration for postgraduate veterinary education.

For all programs identified, annual salary and hospital name, city, state, and zip code were recorded. If a salary range was listed, the amount pertaining to a first-year resident or the lower end of the range was recorded. For LACM programs stating that compensation was based on NIH National Research Service Award stipend levels, \$53,760 was used as the 2021 stipend for a postdoctoral trainee with 0 years of experience. ${ }^{20}$ Additional information recorded but not used in analyses included notes regarding opportunities to earn additional cash compensation. Program listings were checked to ensure the obtained information pertained to the training year beginning in 2021 .

\section{Estimated net income, living wage, income surplus, and hourly wage}

For each program included in the study, estimated net income was calculated with a free online tool designed to estimate annual take-home pay after federal and state taxes. ${ }^{21}$ For these calculations, marital status was classified as single, location was determined on the basis of the program zip code, pay frequency was set to annual, and federal and state allowance claims were set to 1 to minimize deductions. No additional withholdings or deductions were included. The resulting estimated annual take-home pay was recorded as estimated net income.

The online Massachusetts Institute of Technology Living Wage Calculator ${ }^{22}$ was used to estimate the regional living wage for each program. The living wage reported by the Living Wage Calculator assumed fulltime work (ie, $40 \mathrm{~h} / \mathrm{wk}$ and $52 \mathrm{wk} / \mathrm{y}$ ), accounted "only for the basic needs of a family," and was described as 
"the minimum income standard that, if met, draws a very fine line between the financial independence of the working poor and the need to seek out public assistance or suffer consistent and severe housing and food insecurity" and therefore was "perhaps better defined as a minimum subsistence wage for persons living in the United States." 22 For each program, the living wage was determined at the county level for a single adult with no children. The legal minimum wage for the county of each program was recorded. Other data recorded from the calculator consisted of required annual income (RAI) before and after taxes. These values represented projected income required to meet annual individual living expenses on the basis of location. These expenses were the basis of the living wage estimates and included estimates associated with food, housing, transportation, medical, civic, and other costs. ${ }^{22}$ For complex expenses such as medical care, the tool assumed employer-sponsored health-care coverage and then estimated costs associated with individual contribution, medical services, drugs, and supplies.

Income surpluses before and after taxes were then calculated. Income surplus before taxes was calculated as the stated annual program salary minus the RAI before taxes. Income surplus after taxes was calculated as the estimated net income minus the RAI after taxes. Income surpluses before and after taxes were used to indicate income potentially available to interns and residents for costs beyond minimum subsistence living, such as costs associated with, but not limited to, caring for a pet, funding a gym membership, contributing to personal savings, socializing, purchasing prepared foods during busy work weeks, and traveling. A negative income surplus indicated a higher cost of living relative to salary, potentially creating or contributing to personal debt.

The American Association of Veterinary Medical Colleges previously reported the mean \pm SD number of hours worked per week as $61.2 \pm 11.6 \mathrm{~h} / \mathrm{wk}$ for veterinary residents and $66.4 \pm 12.9 \mathrm{~h} / \mathrm{wk}$ for veterinary interns. ${ }^{18}$ Hourly wage based on a 52 -week calendar year and pretax remuneration was calculated for residents for work weeks of 50, 60, and $70 \mathrm{~h} / \mathrm{wk}$ (ie, mean number of working hours per week and 1 SD above and below the mean). Hourly wage was calculated for interns for work weeks of 50, 60, 70, and $80 \mathrm{~h} / \mathrm{wk}$ to obtain a similar range of estimates. Hourly wage for each group at each number of working hours per week was then compared with the hourly living wage to determine the financial return above or below a living wage provided by the training programs.

\section{Data analysis}

Institutions that offered residency programs in multiple categories were included in the analyses only once, unless the salary offered differed between programs by $>\$ 1,000$ or the institution offered training at different program locations (designated by different zip codes). For example, if an institution offered clini- cal residency programs in small animal surgery, large animal surgery, and small animal medicine, but all offered a salary of $\$ 33,000 / y$, this institution was only included once. This was done to avoid overweighting institutions that offered multiple residency programs.

Residency program data were calculated for the 4 clinical residency program categories (small animal surgery, small animal medicine, large animal surgery, and emergency medicine and critical care). Descriptive statistics were calculated for program annual salary, income surplus before taxes, income surplus after taxes, and hourly wage at each increment of weekly working hours minus hourly living wage. The same calculations were performed for programs in academia versus private practice. Descriptive statistics were also calculated for all LACM programs, all small animal rotating internships, and small animal internships in academia versus private practice.

All data were tested for normality with the D'Agostino-Pearson normality test. Program annual salary, income surpluses before and after taxes, and hourly wages at each increment of weekly working hours were compared between program categories and between programs in academia versus private practice. For parametric data, a $t$ test with the Welch correction for unequal variances was used; for nonparametric data, the Mann-Whitney test was used. The Spearman nonparametric method was used to test for a correlation between residency program annual salary and residency location living wage.

All statistical analyses were performed with standard software (Prism version 9.1.2 for macOS; GraphPad Software LLC). Values of $P<0.05$ were considered significant.

\section{Results}

Data were collected for 34 residency programs in small animal surgery, 15 in large animal surgery, 34 in small animal medicine, and 33 in emergency medicine and critical care. After combining data for institutions that offered residency programs in multiple categories, data for 54 unique clinical residency programs were analyzed. This consisted of 26 residency programs in academia and 28 in private practice (Table I). For comparison purposes, data were also collected for 36 residency programs in LACM. In addition, data were collected for 141 rotating small animal internships; 21 of these were in academia, and 120 were in private practice (Table 2).

Eight of the 54 (15\%) clinical residency programs had a negative estimated pretax income surplus, and 9 (17\%) had a negative estimated post-tax income surplus. All 36 LACM programs had positive estimated pretax and post-tax income surpluses. Thirty-one of the 141 (22\%) small animal rotating internship programs had a negative estimated pretax income surplus, and 45 (32\%) had a negative estimated post-tax income surplus.

At a work week of 60 h/wk, 47 of 54 (87\%) clinical residency programs, 15 of 36 (42\%) LACM pro- 
Table I-Income data (US dollars) for clinical residency programs in small animal surgery, large animal surgery, small animal internal medicine, and emergency and critical care in academia $(n=26)$ and private practice $(28)$ and for residency programs in laboratory animal and comparative medicine (LACM; 36).

\begin{tabular}{|c|c|c|c|c|}
\hline Variable & Mean \pm SD & Median & Minimum & Maximum \\
\hline \multicolumn{5}{|c|}{ All clinical residency programs } \\
\hline Annual salary & $\$ 39,903 \pm 10,124$ & $\$ 36,000$ & $\$ 28,000$ & $\$ 75,000$ \\
\hline Pretax IS & $\$ 7,786 \pm 9,426$ & $\$ 5,950$ & $-\$ 10,785$ & $\$ 44,370$ \\
\hline Post-tax IS & $\$ 4,650 \pm 6,753$ & $\$ 3,083$ & $-\$ 9,674$ & $\$ 29,396$ \\
\hline \multicolumn{5}{|c|}{ Hourly wage minus hourly living wage } \\
\hline $50 \mathrm{~h} / \mathrm{wk}$ & $\$ 0.00 \pm 3.80$ & $-\$ 0.67$ & $-\$ 8.50$ & $\$ 14.12$ \\
\hline $60 \mathrm{~h} / \mathrm{wk}$ & $-\$ 2.55 \pm 3.27$ & $-\$ 3.05$ & $-\$ 10.71$ & $\$ 9.31$ \\
\hline $70 \mathrm{~h} / \mathrm{wk}$ & $-\$ 4.38 \pm 2.92$ & $-\$ 4.70$ & $-\$ 12.29$ & $\$ 5.87$ \\
\hline \multicolumn{5}{|c|}{ Clinical residency programs in academia } \\
\hline Annual salary & $\$ 34,446 \pm 4,029$ & $\$ 33,702$ & $\$ 28,000$ & $\$ 44,786$ \\
\hline Pretax IS & $\$ 4,264 \pm 3,936$ & $\$ 4,429$ & $-\$ 2,798$ & $\$ 11,975$ \\
\hline Post-tax IS & $\$ 2,458 \pm 2,867$ & $\$ 1,920$ & $-\$ 2,161$ & $\$ 8,729$ \\
\hline \multicolumn{5}{|c|}{ Clinical residency programs in private practice } \\
\hline Annual salary & $\$ 44,971 \pm 11,439$ & $\$ 42,350$ & $\$ 33,000$ & $\$ 75,000$ \\
\hline Pretax IS & $\$ 11,056 \pm 11,706$ & $\$ 7,545$ & $-\$ 10,785$ & $\$ 44,370$ \\
\hline Post-tax IS & $\$ 6,686 \pm 8,543$ & $\$ 4,759$ & $-\$ 9,674$ & $\$ 29,396$ \\
\hline \multicolumn{5}{|l|}{ LACM programs } \\
\hline Annual salary & $\$ 51,370 \pm 5,525$ & $\$ 52,704$ & $\$ 38,000$ & $\$ 7 I, 000$ \\
\hline Pretax IS & $\$ 16,672 \pm 5,105$ & $\$ 18,434$ & $\$ 5,364$ & $\$ 24,295$ \\
\hline Post-tax IS & $\$ 10,748 \pm 3,957$ & $\$ 12,023$ & $\$ 1,705$ & $\$ 17,424$ \\
\hline \multicolumn{5}{|c|}{ Hourly wage minus hourly living wage } \\
\hline $50 \mathrm{~h} / \mathrm{wk}$ & $\$ 3.09 \pm 2.33$ & $\$ 3.96$ & $-\$ 1.81$ & $\$ 6.52$ \\
\hline $60 \mathrm{~h} / \mathrm{wk}$ & $-\$ 0.20 \pm 2.30$ & $\$ 0.67$ & $-\$ 5.14$ & $\$ 3.09$ \\
\hline $70 \mathrm{~h} / \mathrm{wk}$ & $-\$ 2.56 \pm 2.32$ & $-\$ 1.76$ & $-\$ 7.79$ & $\$ 0.68$ \\
\hline
\end{tabular}

IS = Income surplus.

Pretax IS was calculated as annual program salary minus required annual income (calculated with the Massachusetts Institute of Technology Living Wage Calculator ${ }^{22}$ ) before taxes. Post-tax IS was calculated as estimated net income (calculated with a free online tool designed to estimate annual take-home pay after federal and state taxes ${ }^{21}$ ) minus required annual income after taxes.

Table 2-Income data for small animal rotating internship programs in academia $(n=2 I)$ and private practice $(I 20)$.

\begin{tabular}{|c|c|c|c|c|}
\hline Variable & Mean \pm SD & Median & Minimum & Maximum \\
\hline \multicolumn{5}{|c|}{ All internship programs } \\
\hline Annual salary & $\$ 39,824 \pm 9,813$ & $\$ 38,000$ & $\$ 25,000$ & $\$ 70,000$ \\
\hline Pretax IS & $\$ 5,829 \pm 8,119$ & $\$ 4,400$ & $-\$ 9,092$ & $\$ 40,661$ \\
\hline Post-tax IS & $\$ 3,497 \pm 6,302$ & $\$ 2,350$ & $-\$ 9,606$ & $\$ 27,959$ \\
\hline \multicolumn{5}{|c|}{ Hourly wage minus hourly living wage } \\
\hline $50 \mathrm{~h} / \mathrm{wk}$ & $-\$ 1.02 \pm 3.15$ & $-\$ 1.57$ & $-\$ 7.50$ & $\$ 12.81$ \\
\hline $60 \mathrm{~h} / \mathrm{wk}$ & $-\$ 3.58 \pm 2.72$ & $-\$ 3.94$ & $-\$ 9.58$ & $\$ 8.33$ \\
\hline $70 \mathrm{~h} / \mathrm{wk}$ & $-\$ 5.40 \pm 2.46$ & $-\$ 5.69$ & $-\$ 11.07$ & $\$ 5.12$ \\
\hline $80 \mathrm{~h} / \mathrm{wk}$ & $-\$ 6.77 \pm 2.31$ & $-\$ 6.85$ & $-\$ 12.19$ & $\$ 2.72$ \\
\hline \multicolumn{5}{|c|}{ Internship programs in academia } \\
\hline Annual salary & $\$ 29,887 \pm 3,665$ & $\$ 28,000$ & $\$ 25,000$ & $\$ 36,000$ \\
\hline Pretax IS & $-\$ 1.48 \pm 3,995$ & $-\$ 1,203$ & $-\$ 5,136$ & $\$ 6,879$ \\
\hline Post-tax IS & $-\$ 592.90 \pm 2,899$ & $-\$ 1,290$ & $-\$ 4,769$ & $\$ 4,688$ \\
\hline \multicolumn{5}{|c|}{ Internship programs in private practice } \\
\hline Annual salary & $\$ 41,564 \pm 9,516$ & $\$ 40,000$ & $\$ 27,000$ & $\$ 70,000$ \\
\hline Pretax IS & $\$ 6,850 \pm 8,235$ & $\$ 5,178$ & $-\$ 9,092$ & $\$ 40,661$ \\
\hline Post-tax IS & $\$ 3,865 \pm 6,005$ & $\$ 2,741$ & $-\$ 9,606$ & $\$ 27,959$ \\
\hline
\end{tabular}

See Table I for key.

grams, and 130 of 141 (92\%) small animal rotating internships had a negative difference between hourly wage and hourly living wage. For the same number of hours worked per week, 9 of $54(17 \%)$ clinical residency programs, 0 of 36 (0\%) LACM programs, and 20 of 141 (14\%) small animal rotating internships had a negative difference between hourly wage and local minimum wage.

Clinical residency programs in academia had significantly lower annual salaries $(P<0.001)$, estimated pretax income surpluses $(P=0.007)$, and estimated post-tax income surpluses $(P=0.002)$ than did clinical residency programs in private practice (Figure I). The estimated difference between hourly wage and hourly living wage was also significantly lower for residency programs in academia than for residency programs in private practice for work weeks of $50 \mathrm{~h} / \mathrm{wk}(P=0.014)$ and $60 \mathrm{~h} / \mathrm{wk}(P=0.038)$, but no difference was evident for a work week of $70 \mathrm{~h} / \mathrm{wk}(P=0.09)$. Similarly, clinical residency programs overall had significantly lower salaries and pretax and post-tax income surpluses (all $P<0.001)$, compared with LACM programs. 
Small animal rotating internship programs in academia had significantly lower annual salaries, estimated pretax income surpluses, and estimated posttax income surpluses than did internship programs
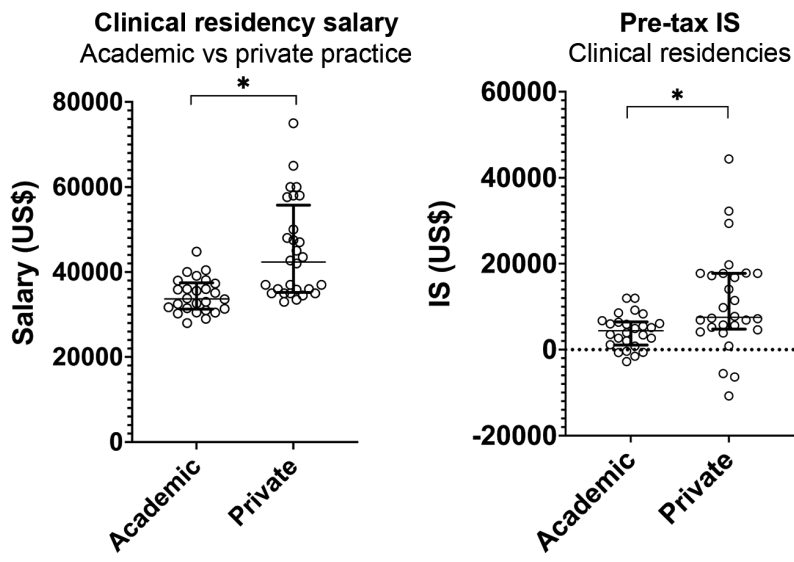

Figure I-Scatterplots of annual salary and pretax income surplus for clinical residency programs in small animal surgery, large animal surgery, small animal internal medicine, and emergency and critical care in academia $(n=26)$ versus private practice $(28)$. In each graph, the long horizontal bar represents the median and the whiskers represent the interquartile (25th to 75th percentile) range. Pretax income was calculated as annual program salary minus the required annual income, prior to taxes, for a living wage in the region where each program was located. IS = Income surplus. *Values were significantly $(P<0.05)$ different.

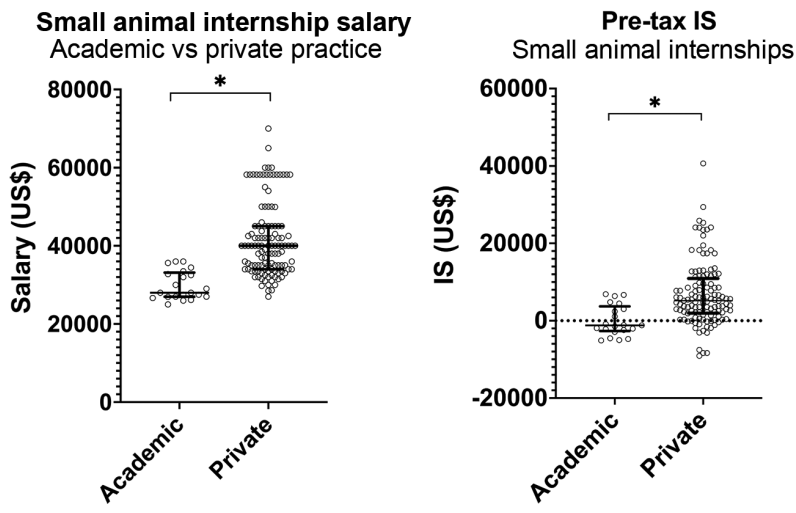

Figure 2-Scatterplots of annual salary and pretax income surplus for small animal rotating internship programs in academia (n $=2 \mathrm{I}$ ) versus private practice (I20). See Figure I for key.
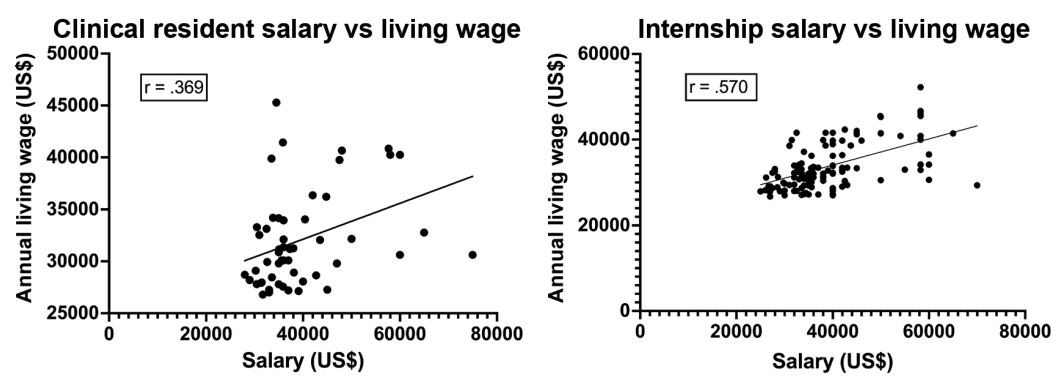

Figure 3-Scatterplots of program annual salary versus annual living wage for clinical residency programs in small animal surgery, large animal surgery, small animal internal medicine, and emergency and critical care (left) and for small animal rotating internship programs (right). In each graph, the solid line represents the Spearman correlation. in private practice (all $P<0.001$; Figure 2). The estimated difference between hourly wage and hourly living wage was also significantly lower for internship programs in academia than for internship programs in private practice for work weeks of $50 \mathrm{~h} / \mathrm{wk}(P<$ $0.001)$ and $60 \mathrm{~h} / \mathrm{wk}(P=0.017)$, but no difference was evident for work weeks of $70 \mathrm{~h} / \mathrm{wk}(P=0.08)$ and $80 \mathrm{~h} / \mathrm{wk}(P=0.38)$. Annual salaries for small animal rotating internship programs were not significantly $(P=0.940)$ different from those for clinical residency programs, nor did pretax $(P=0.091)$ or post-tax $(P$ $=0.091)$ income surplus differ significantly between small animal rotating internship programs and clinical residency programs.

For clinical residency programs, there was a weak correlation between annual salary and regional living wage $(r=0.369 ; 95 \% \mathrm{CI}, 0.103$ to $0.584 ; P=$ 0.006; Figure 3). For small animal rotating internships, there was a moderate correlation between annual salary and regional living wage $(r=0.570 ; 95 \%$ CI, 0.443 to $0.675 ; P<0.001)$.

\section{Discussion}

The investment in obtaining a veterinary medical degree is substantial, and the economic return is not reliably favorable. ${ }^{6}$ Residency training, although not necessarily internship training alone, may facilitate a more positive return, ${ }^{23,24}$ but the time required prolongs the period of financial instability by adding years of low wages, often referred to as a period of lost income. By standardizing salaries through the lens of local living wage, we estimated the degree to which postgraduate veterinary trainees experienced financial hardship during their first year in an internship or residency program. For some trainees, the amount of money they could expect to earn during postgraduate training did not meet the minimum income standard for a single, childless person in the area in which they would live. This disparity could be expected to create or contribute further to personal debt. For a smaller subset, the hourly wage they received would be below the legal minimum wage in the area. There were some programs, most commonly in private practice or LACM, that were more successful in providing trainees with a living wage. While there are implicit, and sometimes necessary, financial and personal life sacrifices that come with choosing postgraduate training, the implications for mental health and potential bias that such financial stress can produce should not be underestimated and, therefore, invite deeper consideration into current remuneration practices.

For many internship and residency programs evaluated in the present study, hourly wage based on the number of hours typically worked per week was lower than the hourly living wage. It is reasonable to expect that 
the difference between hourly wage and living wage would be negative at some number of working hours beyond $40 \mathrm{~h} / \mathrm{wk}$, given that low wages are typically associated with jobs regulated by $40-\mathrm{h} / \mathrm{wk}$ limits and enforcement of overtime pay regulations. However, the Fair Labor and Standards Act of 1938 includes an exemption in section 13(a)(1) for "learned professional employees" that allows certain individuals, such as those pursuing specialized intellectual instruction in medicine, to be exempted from minimum wage and overtime pay regulations. Our findings regarding hourly wage versus minimum wage were only intended to quantitatively reflect the way in which work time was compensated, compared with compensation for theoretical employment elsewhere. Although working more hours does not increase the living wage requirement, working more hours should theoretically increase one's ability to improve one's living conditions. It was implicit in our objective to describe the relationship between the financial value of the work that interns and residents are required to perform relative to their ability to live sustainably in the communities in which they are employed. Volk et $\mathrm{al}^{11}$ reported that inadequate financial reward for work is among the factors leading to burnout among veterinary health-care professionals.

Some programs evaluated in the present study offered additional compensation through emergency shiftwork or for certain on-call events. We believe that all postgraduate trainees subject to the Fair Labor and Standards Act exemption should be granted the ability to supplement their income. Still, with typical work weeks of $>60 \mathrm{~h} / \mathrm{wk}$, it is unlikely that most individuals will have the time or energy to participate in additional labor, and any financial reward received through added shiftwork might be negated by exhaustion and lost time for other personal matters. Exhaustion resulting from additional work hours may contribute substantially to sleep debt and its associated negative impacts on mental and physical health and may increase the risk for medical errors. ${ }^{25,26}$ Moonlighting can be a financial and educational bonus $^{27}$ but may also present a situation of unequal opportunity. ${ }^{28}$ For example, residents in emergency medicine and radiology have skill sets that would allow them to work during off-hours, whereas residents in large animal surgery would have almost no ability to moonlight. The Accreditation Council for Graduate Medical Education implemented rules limiting work hours for all residents in human medicine in 2003 and have updated and modified those rules to meet the evolving needs for education and personal well-being. For programs struggling to offer higher salaries but looking to improve working conditions, a larger discussion about the intersection of time and compensation is warranted.

In the present study, we showed an average annual salary of $\$ 51,370$ for individuals beginning an LACM residency program in 2021 and found that annual salary, pretax income surplus, and post-tax sur- plus were all significantly higher for LACM programs than for clinical residency programs. The American Association of Medical Colleges reported that in 2020, the mean stipend was $\$ 58,921$ for medical residents in postgraduate year 1 and $\$ 61,167$ for those in postgraduate year $2 .{ }^{29}$ These trainees are also exempt under the Fair Labor and Standards Act, yet comparisons to clinical residency programs in veterinary medicine are obvious. Most LACM programs are funded by the US government through NIH salary stipends, whereas Medicare, Medicaid, and, to a lesser extent, the Veterans Administration pay a large portion of the costs associated with training residents in human medicine. Although no federal insurance programs exist to help fund the education of veterinary clinical specialists, the standards set out by the government for remuneration of postgraduate medical science professionals exempt from the Fair Labor and Standards Act may provide a helpful guideline. Future efforts to subsidize training may also be useful in offsetting costs, particularly for academic institutions.

Income surplus was used in the present study to estimate the amount of money beyond a subsistence wage that postgraduate trainees would have to live on when controlling for regional cost of living. The models used to calculate estimated net income ${ }^{21}$ and $\mathrm{RAI}^{22}$ used the same general assumptions about federal and state taxes and included no additional pretax or post-tax deductions. However, the 2 models differed in small ways and ultimately generated somewhat different data. Therefore, differences in estimated pretax and post-tax income surpluses in the present study should be considered a range and not a specific number. The post-tax income surplus may more closely reflect money available for monthly pay periods, whereas the pretax income surplus provides a more conservative estimate and a perspective on how much income might be recaptured through a tax return.

Importantly, income surplus is only an estimation, because living wages are inexact and do not specifically reflect various living standards (eg, quality and quantity of food and housing) or choices (eg, living with or without roommates or cycling instead of driving). Still, surplus income available for costs beyond minimum subsistence living was very low in the present study, especially for clinical residency programs in academia. Also, although many trainees can defer loan payments during their training, the income surplus available to most residents would not allow for meaningful attempts to pay down educational debts. In fact, for some, the costs of living were higher than wages, potentially contributing to additional debt. Burnout and life satisfaction has been directly linked to financial stability. ${ }^{30,31}$ Combined with the typical stressors of a training program, such as long working hours, compassion fatigue, sleep deprivation, and anxiety, financial stress may contribute to an environment that is psychologically challenging during the early stages of a professional career. ${ }^{32}$ Attributes that have been associated with higher levels 
of well-being and good mental health include traveling for pleasure, socializing, and exercising, ${ }^{10,11}$ yet these activities all require expendable income. Physical health may also suffer from low income; with limited time, trainees often rely on low-cost, ready-made meals, which results in an increased risk of obesity. ${ }^{33}$ When there is time for cooking, the lack of expendable income can result in using cheaper, less nutritious ingredients. A poor diet coupled with a lack of time and resources to exercise leads to deterioration of physical health.

The short-term economic return of an internship or residency has implications for creating patterns of bias or unequal opportunity around those who might pursue postgraduate training. The competitive nature of residency programs in particular may create a monopsony-like market, where employers have the ability to structure income around a gratefully captive audience. Individuals without debt or who have financial support from family, partners, or spouses or other sources of personal wealth may be more comfortable with the temporarily low remuneration, whereas others who have no support or have additional financial obligations may be unable to take on additional years of lost income. Although the ultimate return on investment for completing a residency program might be positive for some specialties, ${ }^{23,24}$ diplomate certification is not universally lucrative, and the initial economic strain may serve as a barrier, most readily enabling those who are already the most financially stable. For any individual who has a family or is planning to start one, the living wage requirement becomes disproportionally higher owing to considerations such as childcare and other costs. Recent studies ${ }^{23,24,34}$ of the 2 largest specialty colleges, the American College of Veterinary Surgeons and the American College of Veterinary Internal Medicine, have demonstrated a lack of racial and ethnic diversity, a low rate of childbirth during postgraduate training, $, 35,36$ and a gender discrepancy in residency applications. ${ }^{37} \mathrm{Al}-$ though myriad factors surely participate in these differences, it is likely that implicit economic bias is a contributing factor. Delayed pregnancy may have its own financial sequelae later on among women requiring assisted reproductive technology or experiencing physical complications during gestation or childbirth. Organizational responsibility is an important part of the interventional process in improving veterinary well-being as well as opportunity and diversity; consideration of the compensation of postgraduate trainees is a critical component of these conversations.

Multiple years of lost income can also have longterm consequences. Training programs do not consistently contribute to retirement savings, and the low incomes often prohibit trainees from beginning any retirement savings programs on their own. Those entering certain specialties will be able to recoup this loss with higher income later in life, but this is not necessarily the case for all trainees in every specialty. Delaying the onset of retirement investing by multiple years can have substantial impacts by the time trainees reach retirement age. Offering $401 \mathrm{~K}$ match- ing programs to residents in 3- and 4-year training programs could help build a more solid foundation for the financial future of young veterinarians.

Resident and intern salaries were significantly higher in private practices, compared with academia, in the present study. The mean salary for individuals in small animal rotating internships in private practice $(\$ 41,564)$ was higher than that for individuals in clinical residency programs in academia $(\$ 34,446)$, and the similarity in compensation between clinical residencies and internships was likely due to the overrepresentation of private practices among all internship programs (120/141). Despite the urban location of many private practice programs, higher salaries were not diminished by the local cost of living, as evidenced by significantly higher pretax and post-tax income surpluses in private practices. Private practices also demonstrated the greatest range in salaries offered (\$33,000 to $\$ 75,000)$, suggesting greater flexibility in compensation. With rare exceptions, private practices do not take on the number of trainees across the wide array of specialties that most academic institutions do; therefore, operational and time expenses directed toward resident compensation and education programs are likely lower overall. Fundamental operational and regulatory differences between academic and private practice business models exist, which may explain the greater flexibility that private practices have in setting salaries. Academic hospitals historically function within an operational model through which a substantial portion of patient care is provided by interns and residents and a large proportion of hospital veterinarians is represented by trainees, so even modest increases in remuneration would have large knock-on effects on budgets. Private practice budgets more likely reflect the fact that most patient care is delivered by experienced veterinarians receiving substantial production-based compensation. In both environments, trainees may represent a recruitment investment that might justify a higher training salary. Budgets of both academic and private practices may need to reform to reflect the changing landscape for the supply and demand of specialists and residency training programs.

In the present study, resident and intern salaries had weak to moderate correlations with regional living wage, suggesting salaries are not often set with an eye toward the local cost of living. The low correlation was likely attributable to the clustering of salaries within a range that was both narrow and similar to the range for regional living wage. This was not a longitudinal study; therefore, the degree to which salaries are adjusted annually to keep up with inflation is unknown. The Massachusetts Institute of Technology Living Wage Calculator is reset annually, ${ }^{22}$ taking into account the rising cost of living. According to the Bureau of Labor Statistics consumer price index, the inflation rate in 2020 was $1.23 \%$ and is projected to be much higher in 2021. ${ }^{38}$ Although inflation fluctuates with time, it is unlikely that resident salaries have been specifically adjusted to keep pace with the consumer 
price index. Determining compensation in a manner that considers current economic environments would be a progressive and important step toward better financial stability for residents and interns.

There were multiple limitations inherent to the present study. Our calculations were meant only as an estimate of the financial health of postgraduate trainees and not an exact accounting. Data were obtained after the 2020-2021 Veterinary Internship and Residency Matching Program match cycle was completed, and programs that had been listed initially and removed prior to the match date were not used in our analysis. By considering the largest specialty training areas, the data set for residencies captured 25 of 26 academic institutions in the US with teaching hospitals that routinely train residents and a large set of private practices. As salaries tend to be standardized across specialty programs in academia, the data presented here reflect most, if not all, varieties of academic-sponsored clinical residency programs (eg, large animal medicine, ophthalmology, and anesthesiology) and may be interpreted accordingly. Only data for first-year resident salaries were used due to variability and lack of transparency regarding annual increases. Hours worked used in our calculations ${ }^{18}$ may have over- or underestimated the actual hours worked, particularly with respect to certain specialties, such as emergency medicine and critical care or LACM. Other qualitative data missing from our analysis were fringe benefits such as subsidized housing, free parking, veterinary care discounts, and equipment provided by the employer. Benefit programs and resources (eg, retirement accounts, health care, libraries, and discounted gym memberships) available in particular academic institutions may be of high quality and value, but these could also not be quantified. Institutions or programs were only counted once in our analysis to avoid disproportionate weighting of academic institutions, which annually offer more programs than private practices. Finally, any discussion about compensation of house officers should recognize that some level of financial compromise is necessary for trainees to receive specialized education and that institutions incur associated costs in terms of money, time, and responsibility to perform this service for the profession.

Postgraduate training is a challenge pursued by veterinarians for any number of positive reasons, such as a desire to advance the field through research, a hope of being able to train future veterinarians, and the goal of becoming an expert in a particular specialty, among others. Training programs, in kind, demand appropriate sacrifices to ensure trainees are properly prepared for the trials ahead of them. Certain stressors are unavoidable, yet the opportunity to comfortably and happily pursue a career trajectory is critical to maintaining sustainability and attracting the best talent that will replenish our educational institutions and solidify skills in new graduates. Providing appropriate compensation to maintain a reasonable quality of life and recognizing the link between financial stress and well-being during training are 2 enormous but manageable hurdles for us to confront to improve the veterinary profession for all.

\section{Acknowledgments}

No third-party funding or support was received in connection with this study or the writing or publication of the manuscript. The authors declare that there were no conflicts of interest.

In memory of a beloved friend, colleague, educator, and family member, Dr. Josh Smith, DVM, DACVECC.

\section{References}

1. Cost Comparison Tool; graduating class of 2021. American Association of Veterinary Medical Colleges. Accessed July 12, 2021. https://www.aavmc.org/becoming-a-veterinarian/ funding-your-degree/cost-comparison-tool/

2. Annual Data Report 2020-2021. American Association of Veterinary Medical Colleges. Updated May 2021. Accessed July 12, 2021. https://www.aavmc.org/about-aavmc/public-data

3. Greenhill LM, Young K. 2020 Intern salaries offered through the VIRMP. Association of American Veterinary Medical Colleges. Updated April 2020. Accessed July 12, 2021https:// www.aavmc.org/assets/Site_18/files/Data/2020\%20 Intern\%20Salaries-Final.pdf

4. Greenhill LM, Young K. 2020 resident trainee salaries offered through the VIRMP. Association of American Veterinary Medical Colleges. Updated April 2020. Accessed July 12, 2021. https://www.aavmc.org/assets/Site_18/files/ Data/2020\%20Resident\%20Trainees-Final.pdf

5. Bain B, Hanson C, Ouedraogo F, et al. 2020 AVMA Report on the Economic State of the Veterinary Profession. American Veterinary Medical Association; 2020.

6. Knippenberg R, Dicks MR, Bain B, Dow M. Estimating the financial return on a veterinary education. J Am Vet Med Assoc. 2015;246(4):422-424. doi:10.2460/javma.246.4.422

7. Face the numbers: moving beyond financial denial. American Psychological Association. Updated February 15, 2015. Accessed July 12, 2021. https://www.apa.org/topics/stress/ money

8. Price RH, Choi JN, Vinokur AD. Links in the chain of adversity following job loss: how financial strain and loss of personal control lead to depression, impaired functioning, and poor health. J Occup Health Psychol. 2002;7(4):302-312. doi:10.1037//1076-8998.7.4.302

9. Elbogen EB, Lanier M, Montgomery AE, Strickland S, Wagner HR, Tsai J. Financial strain and suicide attempts in a national representative sample of US adults. Am I Epidemiol. 2020;189(11):1266-1274. doi:10.1093/aje/kwaa146

10. Volk JO, Schimmack U, Strand EB, Lord LK, Siren CW. Executive summary of the Merck Animal Health Veterinary Wellbeing Study. J Am Vet Med Assoc. 2018;252(10):1231-1238. doi:10.2460/javma.252.10.1231

11. Volk JO, Schimmack U, Strand EB, Vasconcelos J, Siren CW. Executive summary of the Merck Animal Health Veterinary Wellbeing Study. J Am Vet Med Assoc. 2020;256(11):12371244. doi:10.2460/javma.256.11.1237

12. Bridgeman PJ, Bridgeman MB, Barone J. Burnout syndrome among healthcare professionals. Am J Health Syst Pharm. 2018;75(3):147-152. doi:10.2146/ajhp170460

13. Balch CM, Shanafelt TD, Sloan JA, Satele DV, Freischlag JA Distress and career satisfaction among 14 surgical specialties, comparing academic and private practice settings. Ann Surg. 2011;254(4):558-568. doi:10.1097/SLA.0b013e318230097e

14. Keeton K, Fenner DE, Johnson TR, Hayward RA. Predictors of physician career satisfaction, work-life balance, and burnout. Obstet Gynecol. 2007;109(4):949-955. doi:10.1097/01. AOG.0000258299.45979.37

15. Klimo P Jr, DeCuypere MG, Ragel BT, McCartney S, Couldwell WT, Boop FA. Career satisfaction and burnout among US neurosurgeons: a feasibility and pilot study. World Neurosurg. 2013;80(5):e59-e68. doi:10.1016/j.wneu.2012.09.009 
16. Golub JS, Weiss PS, Ramesh AK, Ossoff RH, Johns MM III. Burnout in residents of otolaryngology-head and neck surgery: a national inquiry into the health of residency training. Acad Med. 2007;82(6):596-601. doi:10.1097/ ACM.0b013e3180556825

17. Davenport DL, Henderson WG, Hogan S, Mentzer RM Jr, Zwischenberger JB; Participants in the Working Conditions of Surgery Residents and Quality of Care Study. Surgery resident working conditions and job satisfaction. Surgery. 2008;144(2):332-338.e5. doi:10.1016/j.surg.2008.03.038

18. Peterson M. Clinician Wellbeing Initiative: veterinary intern and resident wellbeing study. Presented at: American Association of Veterinary Medical Colleges Annual Meeting; March 4, 2021; Washington, DC

19. Veterinary Internship and Residency Matching Program. American Association of Veterinary Clinicians. Accessed July 2, 2021. https://www.virmp.org/Program/Search

20. Ruth L. Kirchstein National Research Service Award (NRSA) stipends, tuition/fees and other budgetary levels effective for fiscal year 2021. NIH Grants and Funding. Updated January 27, 2021. Accessed September 3, 2021. https://grants.nih. gov/grants/guide/notice-files/NOT-OD-21-049.html

21. Federal paycheck calculator. SmartAsset. Accessed July 1, 2021. https://smartasset.com/taxes/paycheck-calculator

22. Glasmeier AK. Living Wage Calculator. 2020. Massachusetts In stitute of Technology. Accessed July 12, 2021. https://livingwage. mit.edu/

23. Morello SL, Colopy SA, Bruckner K, Buhr KA. Demographics, measures of professional achievement, and gender differences for diplomates of the American College of Veterinary Surgeons in 2015. J Am Vet Med Assoc. 2019;255(11):1270-1282. doi:10.2460/javma.255.11.1270

24. Morello SL, Colopy SA, Chun R, Buhr KA. Work, life, and the gender effect: perspectives of ACVIM Diplomates in 2017 Part 1 - specialty demographics and measures of professional achievement. J Vet Intern Med. 2020;34(5):1825-1836. doi:10.1111/jvim. 15872

25. Landrigan CP, Rothschild JM, Cronin JW, et al. Effect of reducing interns' work hours on serious medical errors in intensive care units. $N$ Engl J Med. 2004;351(18):1838-1848. doi:10.1056/NEJMoa041406

26. Arzalier-Daret S, Buléon C, Bocca ML, Denise P, Gérard JL, Hanouz JL. Effect of sleep deprivation after a night shift duty on simulated crisis management by residents in anaesthesia. A randomised crossover study. Anaesth Crit Care Pain Med. 2018;37(2):161-166. doi:10.1016/j.accpm.2017.05.010

27. Li J, Tabor R, Martinez M. Survey of moonlighting practices and work requirements of emergency medicine residents. Am J Emerg Med. 2000;18(2):147-151. doi:10.1016/s07356757(00)90006-8

28. Baldwin DC Jr, Daugherty SR. Moonlighting and indebtedness reported by PGY2 residents: it's not just about the money! Acad Med. 2002;77(suppl 10):S36-S38. doi:10.1097/00001888-200210001-00012

29. 2020 results of the AAMC Survey of Resident/Fellow Stipends and Benefits. American Association of Medical Colleges. Accessed July 12, 2021. https://www.aamc.org/data-reports/ students-residents/report/aamc-survey-resident/fellowstipends-and-benefits

30. Pulcrano M, Evans SRT, Sosin M. Quality of life and burnout rates across surgical specialties: a systematic review. JAMA Surg. 2016;151(10):970-978. doi:10.1001/jamasurg.2016.1647

31. Miron-Shatz T. "Am I going to be happy and financially stable?" How American women feel when they think about financial security. Judgm Decis Mak. 2009;4(1):102-112. doi:10.2139/ssrn.1329806

32. Bartram DJ, Sinclair JMA, Baldwin DS. Interventions with potential to improve the mental health and wellbeing of UK veterinary surgeons. Vet Rec. 2010;166(17):518-523. doi:10.1136/vr.b4796

33. Alkerwi A, Crichton GE, Hébert JR. Consumption of readymade meals and increased rick of obesity: findings from the Observation of Cardiovascular Risk Factors in Luxembourg (ORISCAV-LUX) study. Br J Nutr. 2015;113(2):270-277. doi: $10.1017 /$ S0007114514003468

34. Demographic data. Veterinary Internship and Residency Matching Program Accessed July 12, 2021. https://www. virmp.org/Content/Match2021Summary.pdf

35. Colopy SA, Buhr KB, Bruckner K, Morello SL. The intersection of personal and professional lives for male and female diplomates of the American College of Veterinary Surgeons in 2015. J Am Vet Med Assoc. 2019;255(11):1283-1290. doi:10.2460/javma.255.11.1283

36. Morello SL, Colopy SA, Chun R, Buhr KA. Work, life, and the gender effect: perspectives of ACVIM diplomates in 2017. Part 2 - the intersection of personal life and professional career. J Vet Intern Med. 2020;34(5):1837-1844. doi:10.1111/ jvim. 15873

37. Morello SL, Genovese J, Pankowski A, Sweet EA, Hetzel SJ. Occupational segregation by gender in veterinary specialties: who we are choosing or who is choosing us. Vet Surg. 2021;50(6):1191-1200. doi:10.1111/vsu.13676

38. US consumer price index by year. Official Data. Accessed July 12, 2021. https://www.officialdata.org/us-cpi 